\title{
Preserving the socio-cultural traditions of rural areas in the social practices of youth
}

\author{
Valentina Rodionova ${ }^{1, *}$, Lyudmila Shvatchkina $^{1}$, Galina Mogilevskaya ${ }^{1}$, Vyacheslav \\ Bilovus ${ }^{1}$, and Valentina Ivashova ${ }^{2}$ \\ ${ }^{1}$ Institute of services industry and business - branch of the Don state technical university in Shakhty, \\ 147, Shevchenko Str., Shakhty, 346500, Russia \\ ${ }^{2}$ Stavropol State Agrarian University, 12, Zootechnicheskiy lane, Stavropol, 355017, Russia
}

\begin{abstract}
The article presents the results of a study of the process of preserving the socio-cultural traditions of rural areas in the social practices of young people. The relevance of issues of social reproduction of traditional culture in the actions of the younger generation is important for the preservation of the identity of local and regional communities. It is a kind of counterbalance to blurring the boundaries of belonging to a social, national, and confessional group. Maintaining adherence to traditional values, lifestyle and the choice of rural settlements by young people for living, it ultimately opposes the processes of rural areas depopulation and ensures their sustainable development.
\end{abstract}

\section{Introduction}

The study of the processes of preserving the socio-cultural traditions of rural areas is one of the topical issues of the identity of local and regional communities, assessing the correlation between globalization and the territorial features of social practices of the population. For rural areas, this topic, in connection with the social group of young people, makes it possible to characterize the commitment to the rural way of life and the readiness for its reproduction. Certain aspects of the topic of preserving the socio-cultural traditions of rural areas in the social practices of young people are reflected in the publications of contemporary authors.

Researcher Z. Beňušková shows the positive practice of social projects in the countryside of Slovakia [1]. The implemented project was aimed at preserving traditional culture and developing social interactions in the local community. The strategy of preserving cultural heritage has a positive effect on the quality of everyday life in rural areas and contributes to the mobilization of economic resources of the territory [1-3]. The findings of the empirical study prove that traditional cultural practices provide leisure selfrealization for local residents and strengthen local identity [4]. In general, the preservation of traditional culture has a positive effect on the perception of the brand of the territory. Thus, the positive socio-cultural practice of preserving the traditional foundations of the local community confirms the relevance of research topics for the stability of the socio-

*Corresponding author: vivashov@mail.ru 
economic situation of the territories. It emphasizes the importance of the reproduction of traditional culture in the social practices of youth for the preservation of the population of rural areas, the development of conditions for local identity

Authors M.S. Yanitskij, A.V Seryj., O.A. Braun, R.V. Kadyrov, T.V. Kapustina offer experience in researching the value orientations of the younger generation in the following regions: Siberia; Far East; Central Russia; Ukraine. The study found that the most distinctive common feature of generation $\mathrm{Z}$ is the priority of independence in terms of opinions and free will, as well as non-compliance with existing traditions [5]. The identification of youth as residents of rural areas characterizes the general orientation of the individual towards the preservation of collectivist and traditional values. On the contrary, living in a megalopolis, ignoring traditional religious affiliation - all this determine the orientation of a person towards individualistic and post-materialistic values [6]. This statement helps to interpret the social practices of young people and their contribution to the preservation of the socio-cultural traditions of rural areas.

An important experience in terms of innovative approaches to the reproduction of traditional sociocultural practices is presented in the article by B. Fanini, A. Pagano, A. Palombini [7]. An example of innovative integration of several approaches to organizing a mobile application in a virtual museum project shows how it is important to fill modern technical communications with content for broadcasting cultural heritage. Young people are in demand for modern interactive cultural and digital practices. Thus, if you embed the necessary content and promote it in the youth environment of agricultural regions, this can be one of the mechanisms for preserving the traditional culture and traditions of rural areas.

Researchers Y. Peng, Z. Ma, D. Zhu, Z. Liu, Q. Meng speak about the educational and environmental effect in the design of the development of rural areas [8]. According to the authors of the article, an integrated approach to the planning and design of rural buildings and the environment forms a traditional ecosystem in rural areas. Such development is designed to meet the modern needs of rural residents and preserve the traditions of the countryside, which are important in defining the uniqueness of the territory and reproducing the identity of rural residents through visual images. Various aspects of the importance of preserving traditional architecture for the formation of identity in the rural community were reflected in the publications K. Klinar, M. Geršič "Traditional house names as part of cultural heritage" [9] and G. Manea, E. Matei, I. Vijulie, O. Cocos, A. Tiscovschi "Tradition and modernity in the romanian rural space. Case study: The arges sub-carpathian foothills" [10].

The researcher N. Chen in the article "Governing rural culture: Agency, space and the re-production of ancestral temples in contemporary China" shows the role of the local community in the process of managing the cultural life of rural settlements [11]. The involvement of rural residents in the social practices of preserving cultural heritage and filling them with modern content is an incentive for expanded social reproduction of the cultural traditions of rural areas. Thus, the rural community takes an active part in the construction of the cultural policy of the state and has a positive effect on the social component of the sustainability of rural areas.

The author of the article, M. Sponte, examines the role of young farmers in the development of agriculture [12]. It is the young leaders of agricultural enterprises who are interested in increasing the competitiveness of agricultural production and improving the social sphere of rural communities. According to the author, it is the young generation of farmers who demonstrate their readiness to ensure food safety, support local production of organic food, and diversify production and other modern trends in the development of the socio-economic sphere of rural settlements. In general, it is the actions of young leaders that will positively affect the level of sustainability of rural areas, including due to the interest of this category of residents in supporting rural tourism, preserving traditional 
culture, and actively engaging in public life [13-15]. The author's conclusions largely confirm the relevance of researchers' attention to the social group of young people in the rural community and the importance of preserving traditional culture in the social practices of young people [16-17].

The review of articles that touches upon the importance and multidimensionality of preserving the socio-cultural traditions of rural areas in the social practices of young people confirms the relevance of the problem under study and makes it possible to determine the methodology and methods of its empirical measurement [18-20].

\section{Materials and methods}

The study of the social practices of young people in the agrarian region and the representation in them of the reproduction of socio-cultural traditions historically inherent in a certain area was carried out in the south of Russia in the Stavropol Territory. In total, within the framework of the field stage of the study, 408 people were interviewed using the method of electronic questioning. In the questionnaire, 25 indicators were used, meaningfully revealing the research topic. Survey was conducted in June 2020.

In the sample, male respondents accounted for $47.1 \%$ of the survey participants, female respondents $-52.9 \%$. The age structure of the sample: respondents $15-17-14.7 \% ; 18-20$ years old $-47.7 \% ; 21-23$ years old $-21.6 \% ; 24-27$ years old $-8.3 \%$; $28-30$ years old $7.8 \%$. According to the level of education, the respondents were represented in the sample by the following groups: secondary education (general education school, lyceum, gymnasium) $-24.5 \%$ of the total number of survey participants; secondary vocational (technical school, college) - 33.8\%; university degree (unfinished degree) - 41.7\%. Among those surveyed, $52.5 \%$ of respondents are currently studying, $22.1 \%$ of respondents are working, $22.5 \%$ of respondents are studying and working at the same time, and $2.9 \%$ of respondents noted that they do not study and do not work. Thus, we can say about the respondents who were included in the sample that they are, in the absolute majority, involved in formal social practices within the framework of interactions at the place of study or work. An important aspect for our research is that almost two-thirds of the survey participants (67.6\%) are indigenous people of the settlements in which they currently live.

\section{Results and discussion}

The preservation of socio-cultural traditions and their social reproduction in accordance with changes in social reality in the current practices of the younger generation is based on attitudes from the family. According to the results of a survey of young people, it can be said that respondents know the life history of 3-4 generations of their relatives: surnames and names, occupation, territorial movements of generations of relatives, and more. The data are presented in the following Table 1. 
Table 1. Distribution of answers to the question about knowledge of the life history of relatives.

\begin{tabular}{|l|l|l|}
\hline Answer options & Number, people & Percentage, \% \\
\hline $\begin{array}{l}\text { I know everything about my } \\
\text { parents }\end{array}$ & 76 & 18,6 \\
\hline $\begin{array}{l}\text { I know everything about my } \\
\text { parents and grandparents }\end{array}$ & 116 & 28,4 \\
\hline $\begin{array}{l}\text { I know about my parents, } \\
\text { grandparents, great- } \\
\text { grandparents }\end{array}$ & 107 & 26,2 \\
\hline $\begin{array}{l}\text { I don't have a complete } \\
\text { information }\end{array}$ & 87 & 21,4 \\
\hline Difficult to answer & 22 & 5,4 \\
\hline
\end{tabular}

Social practices of young people are based on knowledge of historical facts and informational involvement in the processes of preserving the socio-cultural heritage of territories. According to the survey results, $62.6 \%$ of survey participants are interested in and know historical facts about the life and work of famous fellow countrymen.

Table 2 presents data on the knowledge of young people in the history of their native land: traditional holidays, speech characteristics, fairy tales, legends, local national costume.

Table 2. Distribution of answers to the question about the knowledge of the history of the native land (the answers in total exceed $100 \%$, since the respondents could choose several answers).

\begin{tabular}{|l|l|l|}
\hline Answer options & Number, people & Percentage, \% \\
\hline I know the traditions of the holidays & 190 & 45,0 \\
\hline I know the features of speech & 176 & 41,7 \\
\hline I know legends, fairy tales and traditions & 105 & 25,7 \\
\hline I know the peculiarities of the local costume & 83 & 20,3 \\
\hline Other options & 25 & 6,1 \\
\hline
\end{tabular}

The results of the survey indicate a low level of knowledge of young people in the field of traditional speech patterns and holidays characteristic of the locality: awareness varies from $41.7 \%$ to $45 \%$. Young people are even less familiar with the oral samples of the folklore traditions of the territory and the peculiarities of the local costume: the awareness is $25.7 \%$ and $20.3 \%$, respectively. Thus, the absence of an informational component of the preservation of traditional socio-cultural practices shows that young people are not ready to fully reproduce social actions that ensure the transmission of traditional ways of the area.

We can see a certain confirmation of this conclusion in the distribution of answers to the question characterizing the level of interest of young people in information about history, events, books, TV programs about the settlement where they currently live. 
Table 3. Distribution of answers to the question about the level of interest of young people in information on history, events, books, TV programs about the settlement.

\begin{tabular}{|l|l|l|}
\hline Answer options & Number, people & Percentage, \% \\
\hline Information is interesting & 159 & 39,0 \\
\hline Information is more interesting than not & 125 & 30,6 \\
\hline Information is rather not interesting & 78 & 19,1 \\
\hline Information is not interesting & 38 & 9,3 \\
\hline Difficult to answer & 8 & 2,0 \\
\hline
\end{tabular}

The fact that the information is interesting and rather interesting than not interesting was stated by $69.6 \%$ of the survey participants. At the same time, for $19.1 \%$ of respondents, such information is of little interest and for $9.3 \%$ it is not at all interesting.

Socio-cultural practices related to patriotic content are relevant for modern youth. $49.3 \%$ of the survey participants have taken part in events related to patriotic themes over the past year. $42.2 \%$ of respondents answered negatively and $8.5 \%$ could not answer definitely.

Among the organizers of patriotic events in which the respondents took part, $28.0 \%$ belong to local municipalities, $31.8 \%$ belong to educational institutions and $25.1 \%$ to cultural institutions. The federal authorities are identified as organizers of patriotic events by $15.1 \%$ of young people. Among the comments, survey participants name other organizers: sports clubs and public organizations.

In the course of the survey, representatives of rural youth of the Stavropol Territory noted that they are planning leisure activities only in the case of very important events (42.7\% of respondents), they limit themselves to planning activities related to work and study (17.5\% of respondents), they plan all activities (17.0\% of respondents). Only $22.7 \%$ of survey participants said that they never plan leisure activities, i.e. make spontaneous decisions about current socio-cultural practices. Thus, we can say that young people take their leisure activities seriously and responsibly, most of them plan it, moreover, they pay attention to key leisure events and correlate leisure with the main activities - study and work.

Among the main reasons for choosing one or another type of leisure activity in the first place are the desire to relax and cheer up (46.4\% of respondents); on the second - the need for a change of environment (19.9\% of the respondents); on the third - the need for new knowledge (14.7\% of respondents). In addition, a small number of respondents noted among the reasons for choosing leisure time the desire to do nothing (8.1\% of respondents) and the need for communication (8.1\% of respondents).

In the structure of free time of rural youth on weekdays, the leadership was taken by live communication with friends, acquaintances, relatives (noted by $52.9 \%$ of respondents) and virtual communication through social networks and messengers (noted by $45.6 \%$ of respondents). Rural youth also devote a lot of time to other types of leisure activities: $30.9 \%$ of respondents visit cinemas and cafes, $29.9 \%$ of respondents read books, $29.4 \%$ of respondents listen to music, $29.4 \%$ of respondents are engaged in cognitive activities, and go in for sports $26,0 \%$ of respondents, walk and play $26.0 \%$, browse news on the Internet $24.0 \%$. Most of the listed activities are active. An insignificant share of respondents (18.6\%) prefers to just do nothing or watch TV programs (14.2\%).

On weekends, the structure of free time remains approximately the same, but walks $(34.3 \%)$, trips to relatives and nature $(16.2 \%)$, trips to the museum, visits to historical sights of the region and the region are manifested to a greater extent $(9,3 \%)$.

Among the popular events that young people would like to visit, in the first place are virtual excursions to historical sites, museums, exhibitions of folk art and fine arts - noted by $44.1 \%$ of respondents. We see the need to use new approaches in the form of electronic 
communications and technologies to promote the socio-cultural traditions of rural areas. $30.4 \%$ of respondents would like to take part in events dedicated to acquaintance with the historical events of their small homeland. $29.9 \%$ of respondents expressed a desire to hold family events with the participation of representatives of different generations. In leisure practices, $10.3 \%$ of the survey participants would like to see the celebration of a working person, and that can say a lot about the value orientations and attitudes of representatives of the young generation of rural residents.

\section{Conclusion}

Based on the analysis of publications devoted to various aspects of preserving the sociocultural traditions of rural areas in the social practices of young people, we see the relevance of the problem under study not only in Russia, but also abroad in various regions.

Important conclusions of the authors dealing with this topic formed the basis of the research methodology and interpretation of the data obtained. Modern research approaches and concepts are:

- identification of young people as residents of rural areas characterizes the general orientation of the individual towards the preservation of collectivist and traditional values;

- innovative integration of different approaches to the organization of mobile applications with a meaningful filling of communication with cultural heritage to involve rural youth in modern interactive cultural and digital practices;

- preserving the traditions of rural architecture, which are important in determining the uniqueness of the territory and reproducing the identity of rural residents through visual images;

- a high level of interest of young managers of agricultural enterprises in increasing the competitiveness of agricultural production and improving the social sphere of rural communities through the development of rural tourism, preservation of traditional culture, active involvement of all categories of rural residents in public life.

Modern rural youth of the southern region of Russia is attracted by offers of innovative forms of leisure with meaningful content, reflecting the socio-cultural traditions of the territories of their residence.

Young people living in rural areas express a high level of readiness to take an active part in the design of the cultural policy of the region, which will have a positive effect on ensuring the sustainability of rural areas.

\section{References}

1. Z. Beňušková, Project Narodopisna Revue, (4), 287-297 (2019)

2. M.A. Tareau, M. Palisse, G. Odonne, Journal of Ethnopharmacology, 203, 200-213 (2017)

3. S.L. Yeh, Rural China, 13(2), 306-343 (2016)

4. I. Anghel, Cogito, 10(1), 37-46 (2018)

5. M.S. Yanitskij, A.V. Seryj, O.A. Braun, R.V. Kadyrov, T.V. Kapustina, Sibirskiy Psikhologicheskiy Zhurna, (72), 46-67 (2019)

6. Y. Sha, Q. Fu, Inter-Asia Cultural Studies, 19(1), 72-86 (2018)

7. B, Fanini, A. Pagano, A. Palombini, Advances in Intelligent Systems and Computing, 919, 726-736 (2019)

8. Y. Peng, Z. Ma, D. Zhu, Z. Liu, Q. Meng, Ekoloji, 28(107), 921-928 (2019) 
9. K. Klinar, M. Geršič, Acta Geographica Slovenica, 54(SPL. 2), 411-420 (2014)

10. G. Manea, E. Matei, I. Vijulie, et al., Eastern European Countryside, 19(1), 127-151

11. N. Chen, Journal of Rural Studies, 47, 141-152 (2016)

12. M. Sponte, Quality - Access to Success, 15(SUPPL.1), 410-413 (2014)

13. C. Kasimis, A.G. Papadopoulos, Research in Rural Sociology and Development, 19, 263-293 (2013)

14. M. Messmer, H.M. Chuang, Cultural Politics, 9(1), 43-52 (2013)

15. L. Holyoak, 2007 Urban Anthropology 36(1-2) 73-113 (2007)

16. Y. Yan, Culture, Medicine and Psychiatry, 23(1), 75-97 (1999)

17. T. Sivertseva, Central Asian Survey, 18(3), 359-372 (1999)

18. A. Barbič, Agriculture and Human Value, 15(3), 253-265 (1998)

19. V. Ivashova, G. Tokareva, E. Agalarova, et al., IOP Conference Series: Materials Science and Engineering, 775(1), 012020 (2020)

20. V. Goncharov, A. Erokhin, O. Kolosova et al., IOP Conference Series: Earth and Environmental Science, 422(1), 012127 (2020) 